\title{
RESEÑA: CARMÍN ROJO SANGRE. MARÍA ROSAL ${ }^{1}$
}

\author{
María Luisa Calero Vaquera²
}

\section{María Rosal, Carmín Rojo Sangre. Madrid: Colección Literaria Universidad Popular, 2015. ISBN: 978-84-95710-75-8. XXVI Premio Nacional de Poesía “José Hierro", año 2015.}

En este poemario, como en otros libros de María Rosal ${ }^{3}$, aparecen continuas alusiones a mitos y personajes tanto literarios como cinematográficos. Es uno de los sellos permanentes que identifican a la autora, a la que todos reconocemos su formación filológica y humanística. Pero este nuevo libro es, además y sobre todo, un muestrario de "constelaciones familiares": una nueva colmena literaria, una galería de variopintos personajes, no sabemos si imaginarios o reales (lo que no cuenta para la buena literatura...). Y siempre la ironía al fondo, esa chispa ingeniosa tan de María Rosal. Quizás donde se muestra más evidente es en el poema "Detector de mentiras": una abuela (una "mujer látigo, atroz inquisición") que detectaba las mentiras de sus nietas, a propósito de sus experiencias sexuales (la "fiesta de la carne"), con estigmas en la piel. La ironía de la escritora en su más alta expresión, la crítica inteligente de una etapa inicial de la vida por la que todas, con mayor o menor intensidad, hemos pasado. Burla fina también en esa reivindicación del erotismo a los 80 años (“aunque esto pueda no ser bueno..."), en el poema "Tarde de agosto".

\footnotetext{
${ }^{1}$ Fecha de recepción: 30/04/2016.

Fecha de aceptación: 02/04/2016.

${ }^{2}$ Catedrática de Lingüística General, Departamento de Ciencias del Lenguaje, Universidad de Córdoba.; $\triangle$ mlcalero@uco.es.

${ }^{3}$ María Rosal es poeta y profesora Titular de la Universidad de Córdoba. Desempeña en la actualidad la Dirección de la Unidad de Igualdad de su Universidad y la Dirección de la Cátedra de Estudios de las Mujeres Leonor de Guzmán. Ha publicado, entre otros libros de poesía: Tregua (premio Ricardo Molina, 2000), Otra vez Bartleby (Premio Cáceres, 2003 y Premio Andalucía de la Crítica, 2004), Síntomas de la devastación (Premio José Hierro, Alegría, 2007), Discurso del método (Premio Tardor, 2007), Espeleología humana (Premio Aljabibe, 2009). Por su obra Poética de la sumisión. Malos tratos y respuesta femenina en la copla obtuvo el Premio de ensayo Carmen de Burgos (2011).
} 
I.

Por las páginas de este libro vemos pasar la sombra de Franz Kafka ("Vecindad de Franz Kafka"), en unos versos donde la autora nos habla del río de la vida, el melancólico río de Jorge Manrique pasado por el tono angustioso de Kafka, donde somos nosotros, los humanos, quienes sufrimos la metamorfosis y el verdadero transmutado (Gregorio Samsa) es quien nos alimenta por debajo de la puerta. Es la ilusión de la infancia perdida: "Finalmente la vida / no fue un río de aguas cristalinas", que nos recuerda los versos desencantados, y definitivos, de Jaime Gil de Biedma: "Que la vida iba en serio / uno lo empieza a comprender más tarde". Y en el mismo tono de desesperanza, leemos la "Refutación del pesimista": a partir de unos optimistas versos de Rubén Darío ("retrocede engañada la muerte"), María Rosal pone el contrapunto y le enmienda la plana al poeta modernista, pues nos recuerda que la muerte "siempre duerme con las botas calzadas", que "la muerte nunca yerra". Otra manera de decir lo que todos sabemos: que la muerte es lo más cierto, por más que a veces se transmute para tratar de despistarnos: "Es la muerte que avanza / disfrazada de vuelo" ("Licor de la derrota").

La referencia a la clásica Odisea de Homero (“Odisea doméstica”) nos la da la ingenua voz infantil de la narradora. La historia de Ulises recreada, o, más bien, reinventada y fusilada por la abuela, sin duda con la sana intención de entretener la incómoda hiperactividad de sus nietos. Pero la nieta se lo toma a mal cuando descubre, un día en el colegio, que "un tal Homero" le ha fastidiado la odisea vivida por su tatarabuelo, quien estuvo a punto de sucumbir también como Ulises a los cantos de las sirenas.

Es ahora el abuelo quien, en "Casa tomada", sufre las consecuencias de la invasión doméstica de sus hijas, unas mellizas que llevaban veinte años sin hablarse y que la autora compara indirectamente con los cronopios y los famas, aquellos arquetipos irónicos, irreconciliables en su personalidad y en sus costumbres, salidos de aquel exceso de imaginación que se llamó Julio Cortázar. Así que, como los cronopios y los famas, aquellas mellizas "compartieron, por rigurosos turnos, el pasillo y el baño" de la casa del abuelo. 
También dos maneras de entender la vida las encontramos reunidas en el poema "En esta casa no hay fantasmas". Dos maneras opuestas de entender y vivir la vida, contextualizadas en un episodio de la infancia, donde una madre pragmática y contundente impone de un portazo su criterio realista a una niña imaginativa, tan imaginativa como insufrible (a juicio de la madre). Un poema pleno de sucesos sobrenaturales que apenas quedan esbozados y no dichos: una sutileza tras otra para diseñar un escenario digno de Edgar Allan Poe, o de los últimos "Cuentos inquietantes" de Edith Warton. Las "cerezas / rojas como su boca", ingredientes descriptivos de la tarta que ameniza la merienda, en un intento de imponer naturalidad a los prodigiosos acontecimientos que se suceden en la casa, dan cuenta del título del libro, y anuncian el poema que sigue: "Elena, la de Ronda". Se describe aquí a otro familiar, esta vez la hermana de su abuelo, a la que llama por antonomasia "Elena, la de Ronda", que por sus maneras y andanzas nos sugiere la archiconocida y libérrima "Carmen, la de Merimée". Elena, una mujer que no conoce las subordinaciones, sensual, vampira hambrienta de sangre masculina, cazadora nocturna de hombres, perfumada a propósito para sus intenciones (con "un perfume de mantis religiosa"). Aquí es el "carmín rojo sangre” con que pinta sus labios el color que da título al libro. "Elena, la de Ronda", un ser a medio camino entre el imán que atrae y la electricidad que repele, lo mismo que a la vez produce "un punto de pavor y tres de envidia" a la abuela que contaba "la historia y los rumores / de esta mujer sin patria”. Un personaje de vida tan descarriada como la protagonista sin nombre de una de las Historias mínimas (IV. La loca): "Era la loca, la que murió de amor", "la inconcebible", a la vez "manzana y mordedura", con su alborotador perfume también, pero esta vez un añejo "perfume de maderas de oriente". Mujeres que por desviarse de las normas son etiquetadas de "locas" (= dislocadas, fuera del lugar que les corresponde).

Y otra de fantasmas ("Historias mínimas". III. Carcoma): un fantasma con el que toca convivir a los herederos de la casa donde habita, un fantasma "educado en el mejor colegio" pero a la vez exigente, pues hasta pide presidir la mesa. Pero también molesto, como corresponde a los espectros, sobre todo cuando vienen las visitas y hay que abrir las ventanas para airear el tufo que deja. La casa donde habita es una casa con "olor a 
muerte", que finalmente es puesta a la venta "en la sección de anuncios por palabras", con su "olor a polilla" y su fantasma incluido.

II.

Ya en su último libro, Al este del andén (Sevilla, 2013), María Rosal jugaba en su título a asociar literatura y cine. Por allí circulaba el olor a tabaco de Bogart y se contaban amores imaginados con el conde Drácula, con Tarzán, con Supermán... En el libro que hoy reseñamos, Carmín Rojo Sangre, el séptimo arte vuelve a tener una innegable presencia, aunque sea de manera más velada. Así, en "Gloria de los corrales" se nos ofrece una semblanza del abuelo, muestra de una generación sobreviviente a los años del hambre, y en el que la autora destaca como rasgo preeminente que era "carnívoro", a modo de precedente de Hannibal Lecter (El silencio de los corderos). Y, como en un juego de luces del que se beneficia la palabra, María Rosal aprovecha la dilogía del sustantivo "carne" para trasladarnos inopinadamente a las novelas eróticas que el abuelo leía y que la abuela escondía bajo el colchón para sustraerlas a la mirada curiosa de su nieta, con escaso éxito. Anoto esta lograda imagen, a propósito del abuelo granjero: "Adoraba el chisporroteo de los pollos / heraldos de bonanza", que me traslada a la impresionante metáfora de Lorca "los piquetes de los gallos / cavan buscando la aurora". Apenas convocadas por el lenguaje, la imagen y el sonido (como en las salas de cine) se aúnan para obrar el milagro de la comunicación poética.

Y el nombre de la oscarizada actriz Olivia de Havilland resuena en el de la prima Gerarda, alias Sibila de Havilland, "quien decía / leer en las estrellas", y "desde el inapelable / trono de la mesa camilla / repartía ventura / torcía y destorcía destinos y misterios". Una prima mitad chamana mitad santa, la prima Gerarda, a quien la voz poética reza una plegaria final para que siga alimentando "la hoguera de nuestras ilusiones", "ahora y en la hora / de nuestra incertidumbre". Y otra vez "el color de la sangre" en las tarjetas encargadas por la prima Gerarda, donde podía leerse "con caracteres góticos / su nombre de batalla": Sibila de Havilland. 
III.

La singular galería de parientes no acaba aquí. Se nos aparece el "Tío Carlos" como un amor imposible: por incestuoso y por el tiempo que se interpone entre la amante (= la voz que narra), y el personaje amado (= el tío Carlos). Y sobre todo porque se interpone la muerte entre los dos seres, una sincronía de vida y muerte que hará imposible el encuentro entre ellos, como si fueran dos astros incompatibles, los dos rostros del dios Jano que nunca se miran de frente. Y al fondo, París, una ciudad sumida entre dos guerras, y unas pinceladas que nos orientan hacia un lúgubre episodio sucedido años antes en la oscuridad del Sena.

En "Los heraldos del miedo" se narra la capacidad de anunciar desdichas de la abuela Leonor, quien previó, tres días antes de que sucediera, la muerte de su hijo en el Madrid de la guerra civil. Y de ahí el suicidio de la abuela Leonor, que llevó a efecto tras haber envenenado a las bestias en la cuadra ("inundó de amapolas / los arriates del patio": otra vez el rojo de las amapolas, metáfora de la sangre, que nos lleva al color que da título al poemario). Y no acaban aquí los suicidios, que se despliegan ante nuestros ojos en todas sus posibles tipologías: en "Un golpe frío", canción en honor a la bisabuela, que "fue arrojada a este mundo" en mil novecientos, esa fecha de entresiglos coincide con el suicidio del padre, que "se arrojó entre las ruedas / de un coche de caballos". En "Historias mínimas" (I. Ruleta) un antepasado que jugaba a la ruleta rusa: "jugador hasta el tuétano", seductor de "una prima lejana de mi padre", "calavera y guapo como ninguno", un bala perdida que arrasó con el patrimonio a pesar de las novenas que, para su redención, ofrecía su mujer. Pese a todo, y contra todo pronóstico, vivió noventa años... y murió de pulmonía. Pero nada es incompatible con el humor, ni siquiera un asunto tan serio como poner fin a la vida de uno mismo: en el poema titulado "Mal de la piedra" el primo Fernandino aparece como "el miembro más inepto / de nuestra familia", tan inepto que no sabía ni siquiera suicidarse, lo que había intentado en varias ocasiones: tantas que “eran ya proverbiales los suicidios / del primo Fernandino". Quizás no era ajeno a este impulso suicida el mal de la piedra que afectaba al viejo caserón en que habitaba, 
coronado por gárgolas desdentadas y carcomidas, capiteles enfermos y volutas fantasmales. El "mal de la piedra" como causante directo de "la piedra de la locura", aquella que El Bosco nos dejó para siempre retratada en la memoria, o Alejandra Pizarnik nos describió en una larga noche de desvelo ("Toda la noche escribo. / Palabra por palabra yo escribo la noche", La extracción de la piedra de la locura, 1968).

Incluso en este muestrario de parientes, hay referencias a uno de ellos (el primo Alberto) que entra en la categoría de "Parientes improbables", porque existió mucho tiempo atrás, tanto tiempo atrás como para haber sido "salvado de morir en la guillotina". Es un pariente que, como un nuevo convidado de piedra, asiste a las cenas de nochebuena. El rojo de las granadas abiertas nos lleva de nuevo al título del libro.

IV.

Hasta aquí los contenidos, el argumento, las historias que se contienen en este poemario (unas, dislocadas y desconcertantes; otras, divertidas e imposibles...). Pero reconozco que mi manera de parafrasearlo ha sido, sobre todo, un trabajo imperfecto y fallido, de principio a fin. Porque todo este discurso se queda huero y tardará en olvidarse dos segundos si este libro no llegara a leerse. De poco vale aquí la lectura "en diferido" que acabo de hacer. En cambio, leer este poemario en directo es degustarlo, como se degusta y paladea un buen vino. Es entonces, con su lectura (hacia dentro o hacia fuera), cuando aparece la música del texto, la cadencia del engarce de las palabras, el compás de los acentos, la armonía del cómo se dice lo que se dice. Y todo esto es el misterio palpitante de la poesía que solo algunas personas privilegiadas, como María, saben despertar y transmitir. 